\title{
Krytyczna teoria rasy (Critical Race Theory) i obecność koncepcji rasy w kontekście przeszłych i bieżących amerykańskich dyskusji edukacyjnych
}

\author{
KEY WORDS \\ race, racism, Critical \\ Race Theory, Culture, \\ education, American \\ studies, Gates \\ controversy, Brown \\ vs. Board of Education, \\ hate speech, \\ difference, \\ Williams-Bolar \\ controversy
}

\begin{abstract}
Drozdowicz Jarema, Krytyczna teoria rasy (Critical Race Theory) i obecność koncepcji rasy w kontekście przeszłych i bieżących amerykańskich dyskusji edukacyjnych [Critical Race Theory and the Presence of Concept of Race in the Past and Current Educational Debates in the United States]. Kultura - SpołeCzeństwo - Edukacja nr 1, 2012, Poznań 2012, pp. 65-80, Adam Mickiewicz University Press. ISBN 978-83-232-2470-9

The concept of race seems to be, despite the efforts of various political movements of 1960's still present in the public life and education in the Unites States. Contemporary educational debates in America in most cases tackle this problem through the lenses of a specific research approach which takes the concept of race as granted, when examining social relations in the American society. This approach, generally called Critical Race Theory (CRT) had been established in the late 1980's, but its theoretical, methodological and political roots go back to the decade of the Vietnam War and the assassination of Martin Luther King or even further. This paper makes an attempt to deliver a closer look at the CRT and to highlight its most important assumptions and forms of political actions undertaken within the common frame of the racial concept. The Boasian tradition in the American way of conceptualization of race is an important factor in this debate. The past and present educational debates in the USA prove the fact that the idea of race is undergoing nowadays an intensive shift from its biological basis towards economic and social differences making the new conflicts even more visible in the American political landscape today.
\end{abstract}


W czasie, gdy Martin Luther King wypowiadał swoje słynne słowa rozpoczynające się od frazy „Miałem sen...", Stany Zjednoczone były krajem stojącym po raz kolejny na skraju głębokiego przewartościowania społecznych kategorii swojej zbiorowej tożsamości. Amerykańskie media w latach sześćdziesiątych były pełne doniesień o gwałtownych niepokojach społecznych, rewolucyjnym w swoim wyrazie zapale wielu ruchów emancypacyjnych czy też barwnych kontrkulturowych grup młodzieżowych obecnych na ulicach amerykańskich metropolii, jak np. San Francisco. Wyrażane w ten sposób coraz wyraźniejsze niezadowolenie z zastanego społecznego status quo ukierunkowane było zdecydowanie w stronę radykalnej dekonstrukcji ówczesnego konserwatywnego (jak często wówczas zaznaczano) porządku ideowego. Ten polifoniczny dyskurs społeczny w Stanach Zjednoczonych dekady wojny w Wietnamie, hipisowskich eksperymentów $\mathrm{z}$ alternatywnymi formami wspólnot czy też wyrazów młodzieżowego buntu stał się intelektualnym wyzwaniem dla wielu ludzi nauki, którzy zmuszeni zostali do bądź to czynnego w nim udziału, bądź też przynajmniej biernego opowiedzenia się po jednej ze stron tlącego się od dawna konfliktu. Konfliktu, dodajmy, który stanowił w tamtym czasie immanentną część pokoleniowej zmiany tak w sensie makrospołecznym, jak i zmiany generacyjnej w światowej humanistyce.

Kompromitacja moralna takich przedstawicieli dotychczasowych wielkich idei, jak np. Martin Heidegger, zmusiła wielu intelektualistów do przewartościowania poglądów w kwestii konstruowania systemowych modeli myślowych. Pojawiła się konceptualna i moralna pustka, którą należało jak najszybciej zapełnić nowymi treściami. Coraz częściej wskazywano na potrzebę zastosowania metodologii zorientowanej bardziej na fragmentaryczność poznania rzeczywistości społecznej niż na ogląd holistyczny. Teorie średniego i małego zasięgu miały zastąpić rozwiązania systemowe. Te ostatnie, ze względu na próżnię wielkich idei, miały jakoby być pozbawione dłużej prawomocności. Jednym z kierunków badań społecznych, który wyłonił się w kontekście dorobku kontrkulturowych ruchów emancypacyjnych, była formacja, która zwykła być nazywana terminem „krytycznej teorii rasy” (ang. Critical Race Theory) ${ }^{1}$.

Zanim jednak krytyczna teoria rasy pojawiła się na tle amerykańskich debat społecznych i politycznych, krajobraz ideologiczny w tym kraju musiał ulec daleko idącym przemianom tak na poziomie samego przedmiotu debat, jak i intelektualnego pola, w obrębie którego je prowadzono, tj. środowisk akademickich, jak również systemu uniwersyteckiego oraz systemu szkolnictwa średniego i podstawowego. Amerykańskie uniwersytety i szkoły od końca lat pięćdziesiątych podlegały istotnym przemianom wpływającym na głęboką transformację struktur tychże instytucji, jak również ideowych podstaw realizowanego przez nie na wszystkich

\footnotetext{
${ }^{1}$ W dalszej części tekstu posługuję się akronimem KTR dla określenia tej formacji naukowej.
} 
poziomach programu nauczania. Bezpośrednie początki procesu transformacji amerykańskich szkół i uniwersytetów pod względem zróżnicowania rasowego sięgają bezspornie pierwszych decyzji prawnych w sprawie zróżnicowania grup uczniowskich i studenckich. Jedną z fundamentalnych decyzji w tej materii była sprawa sądowa, która w 1954 roku poruszyła społeczeństwo amerykańskie, znana także jako sprawa „Brown kontra Rada Edukacji miasta Topeka”. Określiła ona ostatecznie jako niekonstytucyjny rozdział szkół publicznych ze względu na przynależność rasową i tym samym usunęła prawne podstawy faktycznej segregacji rasowej w amerykańskich instytucjach życia publicznego, funkcjonujące od końca XIX wieku i sprawy „Plessy kontra Fergusson”. Decyzją sądu odrzucono wówczas twierdzenie, iż zasadna jest segregacja rasowa w szkołach publicznych, gdyż opiera się na jakoby wrodzonych (rasowych) różnicach pomiędzy grupami uczniów afroamerykańskich i białej większości. Ten pogląd oddawał w znacznej mierze zbiorowe wyobrażenia o różnicach rasowych w społeczeństwie amerykańskim w tamtym czasie i jednocześnie je obiektywizował jako rzeczywistość daną. Konsekwencje przyjęcia decyzji amerykańskiego sądu w sprawie z 1954 roku okazały się być znamienne nie tylko w obszarze edukacji. Formalne zrównanie szans edukacyjnych czarnej mniejszości i białej większości, szczególnie w stanach południowych, okazało się być również furtką do dalszych działań na polu emancypacji Afroamerykanów. Instytucje państwowe nie mogły dłużej wzbraniać się przed przyjmowaniem przedstawicieli tej mniejszości w swoje struktury. W następnych latach głośne stały się pierwsze przypadki zatrudnienia czarnoskórych Amerykanów w takich instytucjach, jak np. armia czy policja3.

Od początku lat sześćdziesiątych mogliśmy obserwować w Stanach Zjednoczonych nabierający rozpędu proces erozji przekonań na temat różnic rasowych, przynajmniej w dyskursie publicznym i instytucjach życia publicznego. Jego kulminacja przypadła na symboliczny rok 1968, kiedy to również w Stanach Zjednoczonych odczuć można było powiew rewolucyjnego zapału kontrkultury z kontynentalnej Europy. Niejaki James Earl Ray zastrzelił wówczas pastora Martina Luthera Kinga, a amerykańscy czarnoskórzy atleci publicznie wyrazili symbolicznym gestem poparcie dla organizacji „Czarne Pantery” podczas olimpiady w Meksyku.

2 Casus „Plessy kontra Fergusson” z 1896 roku wskazywał na nadrzędność prawa stanowego nad prawem federalnym i sankcjonował zasadę „oddzielnie, ale równi” (ang. separate but equal) w życiu publicznym w USA.

3 Niemniej głośne były wyrażane przez wielu Amerykanów głosy przeciwne integracji. Chodzi tu o przypadek sprzeciwu władz stanowych wobec otwarcia się na Afroamerykanów poprzez protest gubernatora stanu Arkansas Orvala Faubusa, który zanegował możliwość przyjmowania czarnoskórych Amerykanów w szeregi stanowej Gwardii Narodowej. W odpowiedzi na to prezydent Eisenhower sfederalizował tę instytucję, podporządkowując ją rządowi w Waszyngtonie. Innym przykładem tego samego zjawiska jest tzw. „Manifest Południa” (Southern Manifesto) - dokument sygnowany przez 101 polityków z południowych stanów USA sprzeciwiających się procesom integracyjnym. 
Dekada przemian społeczno-kulturowych miała wiele wymiarów, a jednym z ważniejszych miał się okazać ruch na rzecz praw Afroamerykanów. Jego społeczne oddziaływanie było wówczas niewielkie, jednak już dwie dekady później stać miał się on zaczynem nowego społecznego porządku. Porządku, dodajmy, który wyraźnie negował dotychczasowe relacje pomiędzy grupami społecznymi w USA i wskazywał na potrzebę ich radykalnego przedefiniowania.

Amerykański ruch na rzecz emancypacji politycznej, społecznej i kulturowej mniejszości afroamerykańskiej z lat sześćdziesiątych stał bezpośrednio za powstaniem i popularyzacją KTR w drugiej połowie lat osiemdziesiątych. Nie był on jednak jedynym źródłem inspiracji takich autorów, jak np. Derrick Bell. Widzieli oni w procesie kształtowania nowej perspektywy krytycznej dużo szerszy projekt transformacji niewydolnego amerykańskiego systemu, spychającego na margines tych, którzy na skutek szeregu czynników historycznych pozostawiali poza kręgiem głównego nurtu życia kraju. Do politycznego zaplecza KTR zaliczyć można ruch Chicanos (mniejszości hiszpańskojęzycznej) i ruch na rzecz praw mniejszości seksualnych. Proces wyzwalania się grup mniejszościowych w Stanach Zjednoczonych miał polegać na emancypacji zbiorowych tożsamości, zaakcentowaniu możności ich eksponowania w dyskursie publicznym, jak i politycznego uznania wewnętrznego zróżnicowania społeczeństwa amerykańskiego. Pluralizm społeczny i kulturowy miał zatem być w zamierzeniu twórców z kręgu KTR efektem wewnętrznych przemian społeczeństwa amerykańskiego zainicjowanych przez ruch praw obywatelskich. Zanim jednak cel ten został osiągnięty, musiano przezwyciężyć istniejące animozje i głębokie podziały społeczne, które w latach sześćdziesiątych nadal opierały się w Stanach Zjednoczonych na kryteriach rasowych.

Amerykańska koncepcja rasy jest silnie związana ze specyficznym podejściem zarówno do problemu zróżnicowania rasowego, jak i samej definicji kategorii rasy. Ta ostatnia często jest traktowana w sposób zobiektywizowany, nadający porządkowi biologicznemu cechy właściwe problematyce kulturowej. To specyficzne połączenie dwóch przeciwstawnych sobie porządków (natury i kultury) w charakterystyczny sposób definiuje nie tylko typowo amerykańskie podejście do problemu rasy, ale również jest obecne w wielu innych przykładach ideologii rasowej. Jak wskazuje Susan Pitchford, dyskurs rasowy w najbardziej ogólnej formie jest zależny od zachowania tej ciągłości i wyrażenia jej w kategoriach etnicznych i grupowych (Pitchfort, 2000: 2330). Wyłaniająca się z tej przestrzeni kategoria różnicy jest nie tyle kwestią porządkującą, co oceniającą i jakościową. Przykładem tego typu racjonalizowania problemu rasy jest chociażby słynna praca Richarda Hernsteina i Charlesa Murraya The Bell Curve. Zawarta w niej naczelna teza, że istnieje wyraźna zależność pomiędzy poziomem inteligencji mierzalnej testem IQ a przynależnością do określonej grupy rasowej, realizowana jest także na poziomie zjawisk natury edukacyjnej, w tym problemów szkolnych Afroamerykanów. 
Braki edukacyjne czarnych Amerykanów wynikać mają, zdaniem obu autorów, bardziej z czynników dziedziczonych biologicznie niż nabytych poprzez wpływ środowiska i wychowanie. Zanegowanie w tejże tezie kulturowych, społecznych i ekonomicznych podstaw obecnych w amerykańskich statystykach edukacyjnych prawidłowości przekłada się na argumentację ukierunkowaną na udowodnienie zasadności myślenia w zobiektywizowanych kategoriach rasowych. Tym samym The Bell Curve jest wyrazem z jednej strony klasycznych tradycji myślenia o problemie rasy, z drugiej zaś specyficznie amerykańskiego podejścia do tej kwestii. Specyficzny charakter amerykańskiej koncepcji rasy polega w tym przypadku na wyrażaniu przekonania o nieprzerwanym biologiczno-kulturowym continuum, będącym jednocześnie uzewnętrznionym zbiorem cech właściwych danej ludzkiej zbiorowości.

Ten rodzaj partykularyzmu ma swoje źródła w amerykańskiej tradycji badawczej, której jednym z najbardziej znanych przedstawicieli był ojciec amerykańskiej antropologii kulturowej Franz Boas. Ten niemiecki imigrant wpłynął zasadniczo na krystalizację definicji kultury w ujęciu amerykańskiej humanistyki. Definicja ta wskazywała na to, co dla danej społeczności jest charakterystyczne i unikalne: dany wzorzec i kulturowy leitmotiv. Podnosił on w swoich pracach również problem ówczesnej sytuacji Afroamerykanów. W tekście z 1905 roku The Negro and the Demands of Modern Life starał się on wskazać rozwiązanie kwestii poruszonej przez niego samego kilka lat wcześniej ${ }^{4}$. Zdaniem Boasa, jeśli nawet faktycznie biologiczne uwarunkowania ludności czarnoskórej mogą sugerować mniejsze zdolności intelektualne (mniejsza puszka mózgowa niż u innych grup), to nie przekłada się to w żaden sposób na statystycznie ujęte predyspozycje intelektualne. Jak stwierdza Boas: „[...] musimy pamiętać, że korelacja ta indywidualnie [...] jest często przysłaniania innymi przesłankami, a jednocześnie możemy podać szereg przykładów wielkich ludzi o małych mózgach" (Vernon, 1996: 17). Boasowski partykularyzm kulturowy podkreślał zatem nie tyleż zróżnicowanie ludzkich zbiorowości ze względu na obiektywnie dające się wyróżnić wskaźniki, lecz bardziej ze względu na to, co leży w sferze subiektywnego uwewnętrznienia kontekstu kulturowego otaczającego jednostki i grupy. Stanowisko Boasa jest także o tyle ciekawe, iż z wykształcenia był on antropologiem fizycznym, choć usilnie starał się w ciągu swojej akademickiej kariery umniejszyć znaczenie tego faktu. Kontynuując swoje rozważania, dodaje on, iż:

4 Boas w 1894 roku opublikował tekst Human Faculty as Determined by Race, w którym wyrażał pogląd o istnieniu zależności pomiędzy dyspozycjami kulturowymi a porządkiem biologicznym. Z drugiej strony jednak widział ten problem inaczej niż zwolennicy dominującego wówczas darwinizmu społecznego. Dla niego samego zależność ta miała charakter normatywny, nie była zaś odzwierciedleniem uniwersalnego porządku naturalnego i nie miała znamion jakościowych. 
Nie ma najmniejszego powodu, aby nie wierzyć, że Murzyn (oryg. Negro - J.D.), jeśli dać mu możliwość i okazję, będzie doskonale w stanie wypełnić powinności obywatelskie tak jak jego biały sąsiad. Może się zdarzyć, że nie wyda on tak wielu wielkich ludzi, jak przedstawiciele białej rasy, a jego średnie osiągnięcia nie osiągną całkiem średnich osiągnięć białej rasy, lecz będziemy w stanie wskazać niezliczone przykłady ludzi, którym jako [białym] z wadami pozwalamy, aby ciągnęli w dół i uwsteczniali zdrowe dzieci w naszych szkołach publicznych (Vernon, 1996: 17).

Będąc zatem w sytuacji, którą Vernon nazywa „paradoksem boasiańskim”, amerykański badacz stara się skonstruować całościowy ogląd oceny sytuacji edukacyjnej przedstawicieli grup mniejszościowych, takich jak Afroamerykanie. Istotnym elementem tego oglądu jest włączenie już nie tylko partykularnego kontekstu kulturowego, lecz także szeregu innych czynników, również takich jak indywidualne predyspozycje czy też jednostkowe biografie. Ta sfera subiektywnego doświadczenia mogła bowiem uzupełnić w istotny sposób obraz sytuacji wynikający z empirycznych danych statystycznych. Dane te są niepełne i mogą być jedynie czynnikiem zaciemniającym obraz całości. Jak podkreślał Boas w liście do Edwarda T. Devine’a, wyraża on „[...] chęć zebrania większej ilości informacji w odniesieniu do pewnych tropów rasy czarnej posiadających fundamentalne znaczenie dla określenia polityki, jaką powinniśmy przyjąć względem problemu rasy w ogóle" (Vernon, 1996: 18).

Stanowisko Boasa ukonstytuowało akademicki dyskurs na temat rasy w Stanach Zjednoczonych na długie lata i w kontekście przemian lat sześćdziesiątych zepchnęło go w stronę stanowiska konstruktywistycznego. Amerykańska koncepcja rasy operuje dziś tą kategorią w pojęciach mitu i kulturowej symboliki. Problem zróżnicowania rasowego jest zaś ujmowany coraz częściej w kategoriach różnic klasowych i ekonomicznych. Jak udowadnia w pracy The Declining Significance of Race William J. Wilson, to pojęcie klasy częściej niż rasy stanowi we współczesnej Ameryce główną zmienną w relacjach społecznych. Rasa staje się czymś na kształt zbiorowego mitu, ideowej konstrukcji upowszechnianej i reprodukowanej w obrębie pewnych struktur na bazie określonych symboli oraz w politycznie uwarunkowanym i doraźnym celu. Przeniesienie problemu rasy w sferę symboliczną jest także odnoszone do kwestii kulturowej recepcji porządku biologicznego i relacji pokrewieństwa. Klasyczna już analiza amerykańskiego systemu relacji pokrewieństwa autorstwa Davida M. Schneidera, zatytułowana American Kinship, wyraźnie sytuuje ten obszar więzi w polu kulturowych metafor. Zdaniem Schneidera jest to typowe dla społeczeństwa amerykańskiego spojrzenie na relacje biologiczne. Nałożenie na warstwę biologiczną płaszczyzny kulturowej wyraża się chociażby poprzez wszechobecną nomenklaturę pokrewieństwa i koncepcję rodziny (father in law, mother in law itp.). Tłumaczy to w pewnej mierze niechęć środowiska amerykańskich socjologów i ich krytykę wobec wszelkiej ideologii rasowej opierającej 
się na założeniu, iż w zróżnicowanym społeczeństwie amerykańskim jedynie rzekomo najsilniejsze grupy przetrwają wyścig w społecznej strukturze. Potwierdza to stanowisko Stephena Steinberga, który twierdzi w swej pracy Race Relations; a Critique, że amerykański dyskurs rasowy jest nową formą społecznego darwinizmu. Ten specyficzny „język rasy” ma, zdaniem Steinberga, powielać i umacniać, a jednocześnie obnażać, strukturę różnic i nierówności widocznych w społeczeństwie amerykańskim.

W tak zarysowanym kontekście KTR stanowi swoiste przedłużenie tej perspektywy myślowej. Badacze, tacy jak wspomniany już Derrick Bell oraz Mari Matsuda, Patricia Williams, Kimberlé Williams Crenshaw, Richard Delgado, Alan Freeman czy też Lani Guner, realizują swoje autorskie programy krytycznej analizy relacji rasowych we współczesnych Stanach Zjednoczonych z punktu widzenia pragmatycznie rozumianego krytycyzmu. Postawa ta wpisuje się także w dyscyplinarne źródła akademickich podstaw tej formacji. Będąc czynnymi zawodowo prawnikami, Matsuda i Delgado działają w obszarze walki o prawa obywatelskie. Spojrzenie normatywne, a dokładniej: uważna analiza rozwiązań normatywnych, jest zatem dla KTR cechą charakterystyczną, tym bardziej istotną, iż to właśnie w polu prawa realizuje się obecnie jedna $\mathrm{z}$ ważniejszych dyskusji o podłożu rasowym w dzisiejszych Stanach Zjednoczonych (o czym szerzej w dalszej części tekstu).

Na czym polega perspektywa KTR? Większość autorów przypisywanych do tej formacji lub identyfikujących się z nią wyraża duże zróżnicowanie poglądów, lecz można wskazać na zasadnicze zespoły idei kształtujące program KTR. Jak zaznacza Richard Delgado i Jean Stefancic, większość przedstawicieli KTR jest zgodna, iż rasizm nie realizuje się najczęściej poprzez abstrakcyjne pojęcia i dyskurs naukowy. Jest on ideologią obecną i manifestującą się poprzez codzienną społeczno-kulturową praxis, a będące jego konsekwencją akty dyskryminacji to tak zwane akty mikroprzemocy, to znaczy „zwyczajowy sposób załatwiania przez społeczeństwo interesów; zwykłe codzienne doświadczenie ludzi kolorowych w tym kraju" (Delgrado, Stefancic, 2001: 7). Dalej, KTR stawia sobie jako nadrzędny cel wskazanie, iż amerykański system społeczny jest zorientowany na białą większość i dlatego też realizuje w pierwszej kolejności cele i interesy tejże grupy zarówno w sferze ideowej, jak i materialnej. Argument ten jest podstawą szeroko zakrojonej krytyki akcji afirmatywnych realizowanych w amerykańskim szkolnictwie wobec grup mniejszościowych. Polityka rasowego „daltonizmu” jest dla zwolenników KTR kolejnym przykładem operowania kategoriami rasowymi instrumentalizującymi mniejszości etniczne w dyskursie publicznym oraz dalszą formą utajnionego rasizmu (tzw. color-blind racism). Zdaniem takich autorów jak Bell działania te służą jedynie umocnieniu dominującej pozycji białych (a dokładniej: białej klasy średniej) w coraz bardziej zróżnicowanym społeczeństwie amerykańskim. Idea 
ta, nazywana nierzadko „zbieżnością interesów” lub „determinizmem materialnym", sytuuje zatem znaczącą część dorobku ruchów emancypacyjnych po stronie systemu represji. Dzieje się tak, gdyż, zdaniem Bella, kluczowe momenty w walce o równouprawnienie Afroamerykanów były obciążone wpływem i naciskami ze strony grup reprezentujących interesy białych.

W kontrowersyjnym artykule Brown vs. Board of Education and the Interest Convergence Dillema Derrick Bell stawia hipotezę, iż słynny casus prawny stanowił jedynie oczywistą konsekwencję zbieżności interesów Afroamerykanów i białych $\mathrm{w}$ danym momencie historycznym. Tego rodzaju rewizjonizm historyczny jest jednym $\mathrm{z}$ ważniejszych i jednocześnie budzącym największe emocje punktów programu KTR. Pozostaje zatem odpowiedzieć sobie na pytanie: dlaczego nagle tak bardzo zwarty i homogeniczny system, jak amerykańskie prawo, pozwolił w 1954 roku na radykalne zmiany? Jak twierdzi Bell, stało się tak, gdyż

polityki konieczne dla zachowania efektywności szkół zagrażają interesom własnym związków zawodowych nauczycieli i innych grup zainteresowanych zachowaniem status quo. Jednakże udane szkoły mogą dostarczyć nam tej lekcji, iż utworzenie efektywnych szkół dla czarnych musi stanowić nadrzędny cel, bardziej niż drugorzędny skutek integracji. Wielu białych rodziców dostrzega wartość w nauczaniu integracyjnym dla swoich dzieci, jednakże w znaczącej większości postrzegają samą integrację jako jedynie jeden z wielu czynników wpływających na efektywne kształcenie. W pewnym stopniu aktywiści na rzecz praw obywatelskich również akceptują to racjonalne wyczucie priorytetów, dlatego też możliwym jest osiągnięcie pewnej większej rasowej zgody (Bell, 1995a: 26).

Społeczny konsensus w odniesieniu do procesu integracji mniejszości afroamerykańskiej jest jednak o wiele trudniejszy do osiągnięcia niż można by sądzić po postępie zmian legislacyjnych w prawie amerykańskim. O ile poruszona przez Bella sprawa stała się pod wieloma względami punktem przełomowym w stosunkach społecznych w USA, to zakorzenienie dyskursu rasowego jego zdaniem jest zbyt silne, by móc mówić o trwałej zmianie światopoglądowej w kontekście koncepcji rasy. Stała obecność tej koncepcji i rozumowania w jej kategoriach wpisała się na dobre w krajobraz intelektualny Ameryki. W tym ujęciu przełamanie istniejących barier, zwłaszcza na płaszczyźnie edukacyjnej i możliwości kształcenia, jest zadaniem, jakie stawia przed sobą większość autorów spod znaku KTR. Jest to tym trudniejsze, że w przekonaniu Bella, Matsudy czy też Delgado rasizm w społeczeństwie amerykańskim stał się immanentną częścią składową świata społecznych różnic i podziałów. Postulat wykorzenienia tzw. strukturalnego rasizmu jest zatem w obrębie omawianego tu kierunku badawczego jednym z najważniejszych haseł, będących jednocześnie istotnym elementem walki politycznej. Warunkowany strukturalnymi zależnościami rasizm jest zatem autonomicznym mechanizmem społecznego różnicowania i selekcji. Ten deterministyczny ogląd sprawia, że dyskurs rasowy w perspektywie KTR przesuwa się w stronę retoryki bliższej 
kontynentalnemu poststrukturalizmowi realizowanemu w Europie niż czysto amerykańskiemu pragmatyzmowi. To zbliżenie teoretycznych afiliacji KTR i europejskich tradycji badań społecznych stawia badaczy takich jak Bell w centrum dyskusji, której główną osią stają się kwestie: relacje władzy i dominacji, hegemonia, stygmatyzacja społeczna i mechanizmy kategoryzacji, marginalizacja grup mniejszościowych, polityczny charakter dyskursów społecznych czy też kulturowa semiotyka znaczących elementów tychże dyskursów. Dlatego też użycie tzw. „mowy nienawiści" (ang. hate speech) jawi się w tym ujęciu jako naturalna konsekwencja czy też znaczeniowe przedłużenie strukturalnej zależności ideologii rasowej obecnej w życiu mieszkańców USA.

Mowa nienawiści i jej praktyczne manifestacje są na płaszczyźnie edukacyjnej obecne na co najmniej dwa sposoby. Po pierwsze, zjawisko to widoczne jest w przestrzeni szkolnej w obrębie grup uczniowskich. Na tym poziomie mowa nienawiści manifestuje się nie tylko przez językową stygmatyzację członków grup mniejszościowych, lecz również przez piętnowanie wszelkiej odmienności postrzeganej jako zagrożenie integralności i homogeniczności grupy. Dotyczy to odmienności nie tylko definiowanej poprzez kryteria rasowe, lecz także tej wynikającej z mniej empirycznie namacalnych podstaw. Dlatego też przedmiotem agresji jest nierzadko odmienność wynikająca z orientacji seksualnej, poglądów, religii itp. Nawarstwianie się różnych poziomów odmienności replikuje określone wzory zachowań zbiorowych. Akt językowy przekształca się zatem w praktykę społeczną poprzez implicite performatywny charakter mowy nienawiści. Jak wskazuje Judith Butler, mowa nienawiści jest skutecznym działaniem w sensie wywołania określonych społecznych implikacji (Butler, 2010: 89). Ta istotna zależność zawiera się również $\mathrm{w}$ polu ukonstytuowanym przez struktury instytucjonalne. Nie dziwi zatem fakt, że obraźliwe i degradujące określenia płyną zarówno ze strony grupy rówieśniczej, jak i nauczycieli i innych osób reprezentujących urzędy państwowe. To znaczące powiązanie aktów działania językowego i państwa (w tym jego struktur legislacyjnych) jest, zdaniem zwolenników KTR, takich jak Mari Matsuda, charakterystyczne dla kontekstu współczesnej Ameryki. Fakt ten podkreślany jest także przez Butler, która stwierdza, że

[...] państwo produkuje mowę nienawiści. Nie chodzi mi o to, by pociągać państwo do odpowiedzialności za rozmaite zniewagi, epitety i inwektywy krążące obecnie pośród ludzi. Chodzi mi tylko o podkreślenie faktu, że kategoria 'mowy nienawiści' nie może istnieć bez państwowego zatwierdzenia. Sądowniczemu językowi państwa przypisana jest władza ustanawiania i podtrzymywania obszaru tego, co publicznie wypowiadalne, co sugeruje, że państwu przypada funkcja znacznie poważniejsza niż tylko jego ograniczanie. W gruncie rzeczy państwo czynnie wytwarza dziedzinę publicznie akceptowalnej mowy, wytycza granicę między tym, co wypowiadalne i niewypowiadalne, utrzymując władzę wyznaczania i utrzymywania powstałej w ten sposób linii demarkacyjnej (Butler, 2010: 91-92). 
Użycie w mowie nienawiści kategorii różnicy jest zabiegiem nie tylko stylistycznym, lecz także działaniem ontologicznym (w znaczeniu światopoglądowym) i zarazem polityczną deklaracją. Mówi ona, jak obchodzić się z odmiennością oraz jak każda demonstracja nieposłuszeństwa wobec jednolitej wspólnoty winna być karana. Marginalizacja wszelkich odstępstw od normy jest wskazywana jednocześnie jako działanie na rzecz zachowania równowagi systemu. Dzieje się tak na poziomie makro, w odniesieniu do pozycji społeczno-ekonomicznej np. Afroamerykanów, jak i mikro, jak na przykład w przypadku społeczności klasowych w wielu szkołach w USA funkcjonujących w tzw. biednych dzielnicach wielkich amerykańskich aglomeracji. To specyficzne dążenie do zachowania społecznego equilibrium określa, zdaniem takich badaczy jak Bell, głosy sprzeciwu wyrażane przez mniejszości wobec zastanego porządku jako czynnik destabilizujący kruchy konsensus pomiędzy białą większością a grupami takimi jak Afroamerykanie. Każdorazowe wyjście poza ramy ustalonej z góry hierarchii społecznej, opierającej się także na kategoriach rasowych, traktowane jest bowiem jako zamach na idealizowany w tym układzie interes społeczny. W tym kontekście reforma amerykańskiej edukacji i programy mające wspierać edukację mniejszości (w tym akcje afirmatywne) rysowane są jako wyłomy w sprawnie funkcjonującym mechanizmie.

Językowe piętnowanie prób zmiany „porządku rasowego” w USA jest obecnie poza marginesem oficjalnego języka w tym kraju. Słowa takie jak „Nigger” (ang. „czarnuch”) są rzadko spotykane lub całkowicie nieobecne w publicznych wypowiedziach ze względu na sankcje prawne wobec osób stosujących je względem Afroamerykanów. To niewątpliwa zasługa ruchów obrony praw człowieka i ruchów emancypacyjnych lat sześćdziesiątych i siedemdziesiątych. Niemniej problem rasy pozostał istotnym czynnikiem współczesnych konfliktów społecznych w USA. Bolesnym przykładem trwałości tego problemu w świadomości zbiorowej Amerykanów jest przypadek znanego profesora Harvardu i, paradoksalnie, czołowego teoretyka koncepcji rasy i ideologii rasizmu, a także zwolennika perspektywy KTR, Henry'ego Louisa Gatesa Jr.

Profesor Gates został zatrzymany 16 lipca 2009 roku w swoim domu w Bostonie pod zarzutem włamania. Przybyli na miejsce policjanci otrzymali jedynie informację od dyspozytora, iż nieznany czarnoskóry mężczyzna włamuje się do pobliskiego domu. Jak się później okazało, był to Gates, który, wróciwszy z podróży do Chin, nie mógł samodzielnie otworzyć drzwi frontowych i poprosił o pomoc kierowcę taksówki, która go przywiozła. Scenę tę obserwowała sąsiadka Gatesa, która zaalarmowała policję. Interweniującym policjantem był sierżant James Crowley, notabene zajmujący się szkoleniem innych bostońskich policjantów w technikach aresztowań i obchodzenia się z podejrzanymi w taki sposób, aby uniknąć oskarżenia o intencje dyktowane przesłankami rasowymi ${ }^{5}$. To, co wydarzyło się w czasie

\footnotetext{
${ }^{5}$ Chodzi tu o tzw. rasowe profilowanie podejrzanych (ang. racial profiling).
} 
aresztowania Gatesa, wzbudziło ogólnonarodową debatę w USA na temat żywotności uprzedzeń rasowych wśród współczesnych Amerykanów. Gates, uznany amerykański badacz i aktywista polityczny, oraz Crowley, szanowany i doświadczony oficer amerykańskiej policji, wykazali się specyficznym oglądem zaistniałej sytuacji. W obu tych spojrzeniach została wyraźnie zarysowana debata rasowa, która wydaje się być w tym wydaniu zjawiskiem „endemicznie” amerykańskim. Jej istotą był stawiany przez obie strony zarzut kierowania się w swych działaniach pobudkami rasistowskimi przysłaniającymi obiektywne i profesjonalne spojrzenie. Gates twierdził, iż policjant, pomimo wyjaśnień uczonego, zachowywał się agresywnie i nie wierzył, iż czarnoskóry Amerykanin może być właścicielem tak drogiego domu w dobrej dzielnicy, z drugiej strony Crowley uparcie utrzymywał, iż Gates go znieważał jako „niekompetentnego białego”. W sprawie tej głos zajął nawet prezydent USA Barack Obama, potępiając jednoznacznie działania bostońskiej policji6.

Sprawa profesora Gatesa jest tylko jednym z wielu przykładów obecności uprzedzeń rasowych $\mathrm{w}$ społeczeństwie amerykańskim. Umieszczenie tego incydentu w polu edukacyjnym (w tym przypadku akademickim) nie odnosi się jednak tylko i wyłącznie do faktu, iż Gates jest czynnym zawodowo profesorem Harvardu, lecz bardziej do charakteru debaty zainicjowanej tym wydarzeniem. Debata publiczna, która pojawiła się wokół aresztowania amerykańskiego intelektualisty, była przede wszystkim debatą medialną, lecz również wyraźnie przenosiła się w obszar akademickiego umocowania kwestii definicji rasy i stosunku wobec tego problemu takich kierunków jak KTR. Określenie, która z osób bezpośrednio zaangażowanych w zaistniałą sytuację kierowała się pobudkami rasistowskimi, przysłonięte zostało w tym przypadku faktem, iż prowadzone dotąd debaty akademickie okazały się być jedynie pustymi postulatami, których przełożenie na rzeczywistość jest znikome. Ta rozbieżność specjalistycznego (naukowego) języka mówienia o rasie i praktyki społecznej okazać się miała znamienna w odniesieniu do sprawy Kelly Williams-Bolar, młodej czarnoskórej matki ze stanu Ohio, która została skazana prawomocnym wyrokiem za sfałszowanie szkolnych dokumentów aplikacyjnych swoich dzieci. Jej przypadek stał się kolejnym przykładem trwałości specyficznych struktur zależności rasowych, żywych nadal w społeczeństwie amerykańskim. Williams-Bolar podała w dokumentach aplikacyjnych dane swojego byłego męża tylko po to, by jej dzieci mogły dostać się do szkoły w lepszej dzielnicy miasta, zapewniającej znacznie wyższy poziom nauczania, dużo mniejsze nasilenie zjawisk patologicznych (przemoc, narkomania) i dającej lepszy start w kształceniu na etapie akademickim. Jej niezgodne z prawem działania podzieliły amerykańską opinię

${ }^{6}$ Z czego później Obama musiał się publicznie tłumaczyć, gdyż zajął jednoznaczne stanowisko $\mathrm{w}$ tej sprawie, nie zapoznawszy się uprzednio $\mathrm{z}$ faktami. 
publiczną. Z jednej strony domagano się przykładnego ukarania Williams-Bolar, z drugiej zaś wskazywano na to, iż zmuszona została ona niejako do tego kroku poprzez fakt przynależenia do specyficznie uwarunkowanej grupy społecznej, tj. średnio zamożnych czarnoskórych Amerykanów. Ów znaczący rozdźwięk pobudek moralnych czynu Amerykanki odbił się szerokim echem nie tylko w mediach amerykańskich, lecz uświadomił wielu mieszkańcom tego kraju, że „żaden amerykański obywatel nie powinien być zmuszony do dokonywania wyboru pomiędzy złamaniem prawa a zapewnieniem swoim dzieciom dobrego nauczania niezależnie od rasy, narodowości, czy majętności” (Marszał-Norsworthy, 2011:37).

Istotna przyczyna tego stanu rzeczy i upowszechniania się takich przypadków, jak te opisane powyżej, tkwi zarówno w specyficznie amerykańskim sposobie pojmowania rasy, jak i w najbardziej ogólnej definicji jej samej. Opiera się ona na zastosowaniu kategorii różnicy względem określonych ludzkich zbiorowości. Jest to kategoria porządkująca i normatywna zarazem. Odwołuje się do istnienia nie do końca sprecyzowanego porządku naturalnego. Różnica w dyskursie rasowym, w szczególności w Stanach Zjednoczonych, jest jednak określana poprzez zbiór czynników bardziej natury symbolicznej, niż biologicznej ciągłości konstytuującej grupy ludzkie (w tym przypadku rasy). Ta niewspółmierność porządków dyskursu, a właściwie nakładanie na porządek biologiczny elementów o charakterze symbolicznym i znaczeniowym, jest typowym zabiegiem w amerykańskiej tradycji mówienia o różnicy. Tradycji, dodajmy, której korzenie tkwią w modernistycznym projekcie amerykańskiego społeczeństwa przełomu XIX i XX wieku, kiedy to kwestia zróżnicowania kulturowego dotknęła po raz pierwszy w tak rozległym stopniu także monolityczne (jak wówczas uważano) społeczeństwo amerykańskie ${ }^{7}$. Jak twierdzi wspomniany już Henry Louis Gates:

Rasa jest ostateczną metaforą różnicy, ponieważ jej zastosowanie cechuje ogromna dowolność. Sankcja biologii zawarta w różnicy płci, mówiąc krótko, nie obowiązuje i nie może obowiązywać, kiedy mówimy o 'różnicy rasowej'. A przecież beztrosko używamy języka w taki sposób, jakbyśmy chcieli zawrzeć owo poczucie naturalnej różnicy w naszych sformułowaniach. Postępować w ten sposób to raczej wikłać się w niebezpieczne działania języka, które pogłębiają raczej niż łagodzą i rozwiązują złożony problem kulturowej lub ‘etnicznej’ różnicy (Gates, 2004: 383).

Nakreślony przez Gatesa zabieg jest zatem przede wszystkim operacją językową dokonaną przez symbolizację elementów różnicujących w obrębie określonego porządku strukturalnego. Z tym stanowiskiem zgadza się wielu inny współczesnych amerykańskich uczonych podejmujących problem obecności kategorii różnicy we współczesnym społeczeństwie USA. Należy do nich między innymi Walter Benn Michaels, który kwestię tę ujmuje w nieco bardziej ortodoksyjny sposób, łącząc

${ }^{7}$ Mam tu na myśli zjawisko tzw. pierwszej fali Wielkiej Imigracji, dzięki której w Stanach Zjednoczonych wyłoniła się koncepcja „melting pot” (tygla etnicznego) i pierwsze zarysy polityki wielokulturowości. 
dyskurs rasowy z kwestią różnicy ekonomicznej i narastającego rozwarstwienia społeczeństwa amerykańskiego pod względem posiadanego kapitału. W pracy The Trouble with Diversity odwołuje się do tradycji subiektywistycznych, mówiąc, że obecnie problem rasy wynika nie tyle $z$ odgórnie narzuconych sieci relacji rasowych, co z procesów tożsamościowych i idealizacji wszelakiej odmienności. Bycie różnym, specyficznym czy wyjątkowym, jest, jego zdaniem, typowym dla Amerykanów sposobem radzenia sobie z trudnym do zdefiniowania i niejednoznacznym światem. W tym kontekście, jak powiada Walter Benn Michaels: „idea rasy jako konstrukcji społecznej jest zamierzona jako rejestracja faktu, iż pomimo że już dłużej nie wierzymy w rasę jako byt biologiczny, nadal jednak traktujemy ludzi tak, jakby należeli do różnych ras" (Michaels, 2007: 39).

\section{Literatura}

Bell D.A., Jr. (1995a). Brown vs. Board of Education and the Interest Convergence Dillema. [In:] Critical Race Theory. The Key Writings that Formed the Movement. (Eds.) K. Crenshaw, N. Gotanda, G. Peller, Th. Kendall. New York

Bell D.A., Jr. (1995b). Serving Two Masters: Integration Ideals and the Client Interests in School Desegregation Litigation. [In:] Critical Race Theory. The Key Writings that Formed the Movement. (Eds.) K. Crenshaw, N. Gotanda, G. Peller, Th. Kendall. New York

Bonilla-Silva E. (1997). Rethinking Racism: Toward a Structural Interpretation. "American Sociological Review" vol. 62, no. 3, (Jun., 1997): 465-480

Butler J. (2010). Walczące słowa. Mowa nienawiści i polityka performatywu. Warszawa

Delgado R., Stefancic J. (2001). Critical Race Theory. An Introduction. New York and London

Gates H.L., Jr. (2004). Pismo, "rasa" i różnica. [W:] Kultura, tekst, ideologia. Dyskursy współczesnej amerykanistyki. Red. A. Preis-Smith. Kraków

Go J. (2004). "Racism" and Colonialism: Meanings of Difference and Ruling Practices in America's Pacific Empire (2004). "Qualitative Sociology" vol. 27, no. 1, Spring: 35-58

Hatch A.R. (2007). Critical Race Theory. [In:] Blackwell Encyclopedia of Sociology. Ed. by G. Ritzer. New York

Ladson-Billings G., Donnor J. (2009). Krytyczna teoria rasy i jej znaczenie etyczne. [W:] Metody badań jakościowych. T. 1. Red. N.K. Denzin, Y.S. Lincoln. Warszawa

Ladson-Billings G., Tate IV W.F. (1995). Toward a Critical Race Theory of Education. "Teachers College Record" vol. 97, no 1, Fal: 47-68

Marszał-Norsworthy K. (2011). Matczyny przekręt. „Wysokie Obcasy” 16 kwietnia: 36-37

Mazur Z. (2009). Urodzony bohater - Martin Luther King Jr. i jego marzenia. [W:] Czarno na białym. Afroamerykanie, którzy poruszyli Amerykę. (Red.) E. Łuczak, A. Antoszek. Warszawa

McKinley B., Brayboy J. (2005/2006). Toward a Tribal Critical Race Theory in Education. “The Urban Review" vol. 37, no. 5, December: 425-446

Michaels B.W. (2007). The Trouble with Diversity. How we Learned to Love Identity and Ignore Inequality. New York 
Muñoz F.M. (2009). Critical Race Theory and the Landscapes of Higher Education. "The Vermont Connection", vol. 30: 53-62

Pitchford S. (2000). Race. [In:] Gale Encyclopedia of Sociology. (Eds.) E.F. Borgatta, R.J.V. Monthgomery, vol. 4. New York

Rochmann B. (2009). The Gates Case: When Disorderly Conduct Is a Cop's Judgment Call. “Time”, Saturday, 25th July

Scheurich J.J. (1993). Toward a White Discourse on White Racism. "Educational Researcher" vol. 22, no. 8 (Nov.): $5-10$

Sleeter Ch.E. (2001). Preparing Teachers for Culturally Diverse Schools: Research and the Overwhelming Presence of Whiteness. "Journal of Teacher Education" vol. 52, no. 2, March/April: 94-106

Sniderman P.M., Tetlock P.E. (1986). Reflections on American Racism. "Journal of Social Issues" vol. 42: 173-187

Spears A.K. (1978). Institutional Racism and the Education of Blacks. "Anthropology \& Education Quarterly" vol. 9, no. 2, Summer: 127-136

Van Dijk T. (1993). Elite Discourse and Racism. Newbury Park

Vernon W.J. Jr. (1996). Rethinking Race. Franz Boas and His Contemporaries, Kentucky

Yosso T.J. (2005). Whose Culture Has Capital? A Critical Race Theory Discussion of Community Cultural Wealth. "Race, Ethnicity and Education" vol. 8, no. 1, March: s. 69-91

\section{Critical Race Theory and the Presence of Concept of Race in the Past and Current Educational Debates in the United States}

\section{Summary}

When Martin Luther King presented his famous speech beginning with the phrase "I had a dream" America once again stood at the verge of redefining its own values and identity. In the 1960's more and more voices had been heard, which expressed the need to change the sociocultural status quo and the ideological order. This very polyphonic discourse has had a deep impact on the social phenomena occurring in this revolutionary period. Many new social groups emerged in those years, ranging from youth subcultures, through various emancipation groups, ending with paramilitary organizations (like the Black Panthers for example). This was also the time when the American racial concepts were shaken by the social movements, which also tried to redefine the American way of thinking about society itself, its criteria of acceptance and cultural basis. This discourse was full of conflict, in which American education played an important part.

The educational debates of the 1960's were put in the middle of ideological shifts specifically for western thought after 1945. The moral void left by great philosophical authorities, like Martin Heidegger for example, was soon to be filled with new content, including many emancipation postulates for diverse minorities. In the USA, one of the most visible of those minorities was the Afro-Americans. The social, economic, cultural, political and last but not least educational position of many black Americans after WW2 had been shaped since the end of the 19th century by racial and social prejudice, exclusion from social participation and legal acts which separated whites and blacks in the public sphere. The legal aspect of this division 
of American society has its origins in the Plessy vs. Fergusson case from the 1890's. This case undermined the role of federal legislation over state acts and was also the beginning of separation in American schools between the white majority and the people of color. In the 1960's the process of renegotiation of these legal solutions was stimulated by the civil rights movements, an important factor of change these days in the USA. However, this process of social transition had been initiated at least a decade before. In the educational sphere a need emerged in postwar America for groundbreaking changes in the schooling system of the country. The division between whites and blacks had to be overcome if the American society were to adapt to new challenges brought by the future.

Another legal case, in the mid 1950's, had shaken the American public - Brown vs. Board of Education. This time, the socio-political outcome of this case was supposed to be even more far reaching that the infamous Plessy vs. Fergusson. The right for equal education of black Americans was since then a part of the struggle for new democratic standards, including equal rights for all Americans. This case also initiated a specific current in intellectual debates in the country, which later on was known as the Critical Race Theory (CRT). CRT is an ideological formation which originated in this very context of the 1960's (although it emerged in the late 1980's). It puts the American race concept in the middle of its own critical approach toward the sociocultural relations in contemporary America. This race concept might be traced back to the 19th century, when such theorists as Franz Boas conducted their research on the relation between culture and race. According to Boas there is a significant relation between two basic orders in human behavior: the natural order (biology) and the cultural. This relation might be expressed through visible patterns, such as race.

Therefore we may say that Boas's race theory is an important contribution to the analysis of the educational situation of Afro-Americans in the first half of the 20th century. Boas, being caught in a paradox situation (on one hand he points out the relation between race and culture, and on the other he advises his readers to avoid any simple generalizations of this premise), tries to tackle the heart of the matter, that is the questions of how to deal with racial groups, and even further, he asks if we might speak of race as a kind of objective reality at all. His standpoint, revolutionary in his days, did not bring him many followers, but it certainly attracted attention.

However, race treated as objectivity is still today the basis for racial ideologies, which serve as "scientific" proof that the differences between people lie upon nature and not culture. Hernstein's and Murray's book "The Bell Curve" was one of their emanations. Their thesis, that the educational position of black Americans is the simple consequence of their natural lack of adaptation skills, had gathered much critique, but also had been welcomed by many less "politically correct" intellectuals as final evidence of what many Americans see as common phenomena. According to those followers of "The Bell Curve", the education of Afro-Americans is followed by other forms of socio-cultural marginalization. In this manner the reproduction of the marginal social position of blacks is being treated as the consequence of a closer undefined "underdevelopment" of that group. According to Stephen Steinberg this specific social Darwinism is common for the American race concept. Steinberg stresses that this racial discourse itself, as well the public language regarding race and racial minorities, is one of the most important factors strengthening the divisions in American society.

The same view is shared by the most significant authors associated with CRT, such as Derrick Bell, Mari Matsuda, Patricia Williams, Kimberlé Williams Crenshaw, Richard Delgado and Alan Freeman. In their opinion racism does not express itself through academic discourses and abstract terms. It is rooted in the daily social praxis, which is also visible in the acts of the so-called "microviolence". But if CRT authors do not share many common views and opinions, 
we are able to point out at least one with which they all agree. The American social system is oriented on the white majority and that's why it realizes its interests in the first place (as well as in the ideological and material sphere). Racial minorities are being instrumentalized in the public discourse as objects of change, not the participants and subjects of social life. Education practices such as affirmative actions are viewed by Bell or Delgado as another form of the reproduction of the status quo, or what they call "color blind racism". According to Bell, such actions serve only maintaining the interests of whites and are what he calls "materialistic determinism". Therefore we have to change the way we think about race, if we want to overcome this obstacle. The basis of the American race concept, criticized by CRT authors, is taking two different orders of reality (biology and culture) as dichotomous.

Contemporary American educational debates seem to provide us with evidence that the postulates of CRT are still not fulfilled. Two recent cases related to racism have shaken the public in the USA. The arrest of a Harvard professor (and paradoxically also a race theorist), Henry Louis Gates Jr. wrongly taken as a burglar in his own house, as well as the case of a young mother, Kelly Williams-Bolar, who has been accused of fraud as she used her husband's name to give her children the chance to attend a better school outside her own district, show us that American society still takes old race concepts as granted. Regardless of the attempts to change this situation, the deeply rooted devotion to social and cultural differentiation remains as an important factor of social relations in the USA today. The reason for this might be, as stated by Henry Louis Gates, that "race remains an ultimate metaphor of difference because it is characterized by a strong latitude of usage". Gates' statement may also explain why today the language of difference is being examined as the most interesting object of study by many CRT authors. 